El proceso de profesionalización de la traducción y de la interpretación competentes establecen las cualificaciones académicas de acceso a la profesión, así como las destrezas y competencias con que han de contar los profesionales que deseen prestar sus servicios en este ámbito. En el presente artículo se presentará un análisis crítico de los sistemas de acreditación profesional de intérprete jurídico en España (intérpretes jurados e intérpretes judiciales y policiales en plantilla). Este análisis partirá de una serie de consideraciones que la bibliografía especializada resalta respecto de la evaluación de la competencia traductora ya que, como se podrá comprobar, estos sistemas de acreditación en España, giran, fundamentalmente, en torno a ejercicios de traducción.

PALABRAS CLAVE: interpretación en los servicios públicos, interpretación judicial, interpretación policial, traducción-interpretación jurada, traducción jurídica, acreditación profesional, evaluación de la competencia traductora, calidad.

\title{
Cómo acreditar intérpretes a través de la traducción: análisis crítico de la acreditación profesional de intérpretes jurídicos en España
}

Juan Miguel Ortega Herráez

Universidad de Alicante

G. I. GRETI (HUM-737, Universidad de Granada)
Accrediting Interpreters through Translation: Critical analysis of legal interpreting accreditation schemes in Spain.

In numerous countries professionalization in the field of public service translation and interpretation has been linked to the existing accreditation practices. This is how the authorities establish the academic requirements to enter the profession, in addition to the skills and competences that any professional wishing to work in this field must possess. In this article a critical analysis of the professional accreditation systems that exist in Spain for legal interpreters (both sworn interpreters and staff court and police interpreters) is presented. This analysis will be carried out on the basis of a series of considerations regarding translation competence assessment as highlighted by the specialised bibliography in the field. It must be noted that existing accreditation schemes in Spain are mainly built up on translation-focused tests.

KEY WORDS: public service interpreting, court interpreting, police interpreting, sworn translation-interpreting, legal translation, professional accreditation, translation competence assessment, quality. 


\section{INTRODUCCIÓN}

En las recomendaciones que el Consejo euro- peo de justicia y asuntos de interior (Consejo de la Unión Europea, 2009) realizó sobre la Propuesta de Decisión Marco del Consejo relativa al derecho a interpretación y a traducción en los procesos penales, se llamó especialmente la atención sobre aspectos tales como la cualificación, la formación y la inclusión en registros profesionales de todos aquellos llamados a desempeñar tareas de mediación interlingüística e intercultural en entornos jurídico-policiales. La inclusión de estos aspectos en dichas recomendaciones no fue casual, sino que respondía a la equiparación que suele establecerse entre la profesionalización de una actividad y los criterios de acceso a la misma.

En España la ISP todavía se encuentra pendiente de una plena profesionalización y, de hecho, sólo en el ámbito jurídico es posible encontrar sistemas de acreditación profesional, si bien cabría preguntarse si, en su configuración actual, estos sistemas pueden contribuir a esa profesionalización a la que se ha aludido. El análisis de los sistemas de acreditación existentes en nuestro país parte de una breve descripción de los principales problemas que surgen en torno a la cuestión de la evaluación de la competencia traductora. Resulta imposible, por razones de espacio, describir pormenorizadamente sistemas de acreditación existentes en otros países ( $c f$. Ortega Herráez, 2orr: 47-62), lo que también nos hubiera ofrecido un buen punto de partida y referencia.

\section{PROBLEMÁTICA GENERAL DE LA EVALUACIÓN DE LA COMPETENCIA TRADUCTORA Y EN INTERPRETACIÓN}

La correcta evaluación de la competencia traductora plantea no pocos retos, tanto en el marco de los programas formativos en la materia como en la selección de profesionales en determinados ámbitos. A este último respecto, en su obra sobre aspectos curriculares de la traducción, Kelly (2005:I32) plantea una serie de limitaciones de los sistemas de evaluación tradicionales, tanto en el ámbito académico como en los procesos selectivos existentes en los organismos internacionales, ya que suelen girar en torno a la mera realización de una traducción en las típicas condiciones de exámenes (tiempo controlado, texto desconocido, uso o no de referencias, etc.) y la evaluación se reduce a descontar puntos por los errores cometidos tomando como modelo una hipotética traducción perfecta. Según esta autora este tipo de pruebas:

- They are unrealistic, that is they have little or nothing to do with real professional translation situations (prior knowledge of type of text, subject area, possibility of documentary research of all kinds, kind of time pressure, physical environment...).

- They attempt to measure all the skills making up the translator's overall competence at once; they further assume that the product is a fair indication of each of these skills, many of which are process, not product related (Hatim and Mason 1997: 198).

- Criteria for examination text selection are often obscure, unclear, or in the worst of cases, practically non-existent.

- They show intrinsic lack of faith in [...] candidates' responsibilities and trustworthiness.

- This kind of error-based marking does not take into account positive aspects of [candidates'] work [...].

- Criteria for grading and ultimately passing and failing are often not transparent, and certainly not uniform.

- Translations for exams are often unaccom- 
panied by even a minimum contextualization of the task at hand in the form of a translation brief. (Kelly, 2005: 132)

De la misma opinión parece ser Angelelli (2009: I4), quien hace especial hincapié en la relativamente escasa atención que, frente a otras disciplinas, los Estudios de Traducción e Interpretación han prestado a la evaluación de la competencia traductora, lo que parece hacerse más patente aún si cabe fuera de contextos de enseñanza-aprendizaje, como es el caso que nos ocupa. A partir de la bibliografía existente en el desarrollo de instrumentos de evaluación, identifica una serie de parámetros que han de ser tenidos en cuenta en el proceso de desarrollo de dichos instrumentos: naturaleza de la prueba (norm-referenced vs. criterion-referenced ${ }^{\mathrm{T}}$ ), validez (en un sentido amplio, si la prueba mide realmente lo que pretende medir), fiabilidad (el grado de consistencia del instrumento de medida en un constructo dado), autenticidad de la prueba (el que las tareas propuestas guarden una estrecha relación con la actividad que se espera desarrolle posteriormente el candidato) y autenticidad de las tareas (el que el formato de respuesta, la posibilidad de hacer uso de ciertos recursos o de disponer o no dé tiempo para editar o revisar el texto, se asemejen a la situación real de trabajo; en caso contrario, debería tenerse en cuenta para que no constituyan elementos evaluables) (Angelelli, 2009: 15-22).

Así, en su propuesta para sistematizar los sistemas de acreditación profesional de traductores, esta autora parte de la definición del

\footnotetext{
I "The norm reference approach allows for an overall estimate of the ability relative to the other examinees. [...] In the criterion-referenced approach, criterion skills or behaviours are determined and then test specifications are written. This approach is used to see if a test taker has met certain objectives or criteria rather than to see how a test taker does compared to another." (Angelelli, 2009: I6)
}

propio constructo ${ }^{2}$ sobre la base de algunos de los modelos de adquisición de la competencia traductora ${ }^{3}$, más concretamente, sobre subcompetencias tales como la lingüística, la textual, la pragmática y la estratégica. Esto le permite analizar algunos sistemas de acreditación administrados por organizaciones de tipo profesional (American Translators' Association, ATA; National Association of Judiciary Interpreters and Translators, NAJIT; National Accreditation Authority for Translators and Interpreters, NAATI) y plantear ciertas dudas en torno al grado de cumplimiento efectivo que estos sistemas presentan en lo relativo a la definición del constructo, a saber, la propia definición y operativización de la noción de "competencia traductora» y su plena integración en los instrumentos de acreditación. Es por ello que hace un llamamiento a la colaboración entre organizaciones profesionales e investigadores en traducción y en evaluación, al objeto de desarrollar instrumentos que efectivamente logren el objetivo que persiguen.

Hewitt (I995) también plantea que este tipo de pruebas han de asentarse sobre principios que garanticen la fiabilidad y validez del propio sistema. Para ello el sistema de acreditación ha de mantenerse estable en el tiempo y garantizar su comparabilidad tanto entre combinaciones lingüísticas como entre ediciones diferentes. Sólo así se puede lograr que el nivel de exigencia sea siempre el mismo. Además, resulta fundamental que las pruebas incluyan algún componente que mida los conocimientos de

\footnotetext{
2 "A clearly spelled out definition of exactly what a test developer understands to be involved in a given ability. If we are testing an ability to translate, it is important that we first clearly and meticulously define exactly what it is that we are trying to measure." (Angellelli, 2009: 22)

3 Entre los trabajos que esta autora cita se encuentran los de Kiraly (1995), Cao (1996), Schäffner, C. and Adab, B. (2000), Orozco (2008) (cf. Angelelli, 2009).
} 
terminología o conceptos jurídicos claves, e incluso aspectos de orden deontológico, así como pruebas prácticas en las distintas modalidades de interpretación.

En lo que a la estructura de las pruebas se refiere, la literatura consultada recomienda que se administre una prueba inicial eliminatoria (o screening test), que puede adoptar muy distintos formatos ( $c f$. Hewitt, I995: I09-ıाо; Ortega Herráez, 2orr: 47-62). Dada la relativa facilidad y supuesto menor coste que supone su administración, esta prueba facilita una primera selección de los candidatos idóneos, ya que sólo aquellos que la superan pueden acceder a realizar las pruebas centrales de la acreditación, y que son las que miden las destrezas en interpretación o traducción propiamente dichas. Ante el panorama descrito por los autores citados cabría preguntarse en qué grado las pruebas que componen los actuales sistemas de acreditación profesional de intérpretes jurídicos en España presentan algunas de las limitaciones a las que se ha aludido.

\section{SISTEMAS DE ACREDITACIÓN DE INTÉRPRETES JURÍDICOS EN ESPAÑA}

A los efectos del presente trabajo se considerará sistema de acreditación profesional tanto las pruebas o conjunto de pruebas destinadas a conceder algún tipo de habilitación profesional como intérprete y traductor oficial para desempeñar funciones como profesional liberal, como las organizadas para ocupar puestos en plantilla como intérprete-traductor en determinadas instituciones de índole jurídica. Entre las primeras se encontrarían las pruebas que tanto el Ministerio de Asuntos Exteriores y Cooperación (MAEC, I996, 2009), como la Xunta de Galicia y la Generalitat de Cataluña (2000) convocan para habilitar traductores/intérpretes jurados ${ }^{4}$. Entre las segundas se encontrarían las oposiciones que entidades como el Ministerio de Justicia y el de Interior, o algunas CCAA, convocan para proveer puestos en plantilla de traductores e intérpretes en juzgados, comisarías de policía, cuarteles de la guardia civil, etc. Nótese cómo en el caso de España nos encontramos con perfiles profesionales duales (traductor e intérprete), lo que sin lugar a dudas influye en la configuración del sistema de acreditación.

Tradicionalmente ha sido la figura y acreditación profesional del intérprete jurado nombrado por el MAEC la que mayor atención ha recibido en el seno de los Estudios de Traducción e Interpretación en España. Así, se pueden destacar trabajos como la panorámica ofrecida por García-Medall (1998), o los numerosos trabajos de Mayoral, entre los que se puede destacar los que analizan la problemática de la práctica profesional de la traducción jurada (entre otros Mayoral 2000 y 2003), el de Way (2005), el de Vigier (2010) sobre una de las vías de acreditación previstas, e incluso el de Giambruno (1997), que combina el análisis tanto de la acreditación de intérprete jurado como la de intérprete judicial. En cuanto a la acreditación de traductores e intérpretes judiciales, los trabajos realizados (entre otros Ortega Herráez, 2oII; Ortega Herráez et ál., 2007; Arróniz, 2000) también centran su análisis en la estructura general de las pruebas y, a lo sumo, en la temática general de las mismas.

El objetivo de este trabajo es, pues, actua-

4 Nótese que el presente trabajo se ha desarrollado con anterioridad a la publicación del Real Decreto 2002/2009 (BOE 24 de diciembre de 2009) que reforma, entre otras cuestiones, aspectos relativos al acceso a la profesión de intérprete jurado y a su denominación, que en lo sucesivo pasa a ser traductor-intérprete jurado (cf. MAEC, 2009). A pesar de ello, la estructura de las pruebas sigue siendo la misma (cf. MAEC, 20Io). 
TABla i. Sistemas de aCReditación analizados

\begin{tabular}{lll}
\hline Organismo convocante & Objetivo & Año \\
\hline $\begin{array}{l}\text { Ministerio de Asuntos Exteriores y } \\
\text { Cooperación (MAEC) }\end{array}$ & Intérprete jurado (IJ) & 2007 \\
\hline Generalitat de Cataluña (CAT) & Traductor e Intérprete jurado (TIJ) & 2008 \\
\hline Ministerio de Justicia (MJU) & Intérprete-traductor judicial en plantilla & 2008 \\
\hline Ministerio del Interior (MIR) & Intérprete-traductor policial en plantilla & 2002 \\
\hline $\begin{array}{l}\text { Ministerio de Admones. Públicas } \\
\text { (MJU-MIR) }\end{array}$ & Intérprete-traductor policial en plantilla & 2007 \\
\cline { 2 - 3 } Junta de Andalucía (AND) & Intérprete-traductor judicial y policial en plantilla & 2008 \\
\hline
\end{tabular}

lizar este análisis, para dar cuenta de algunos de los cambios acaecidos con la introducción de prácticas de acreditación como traductor e intérprete jurado de lenguas co-oficiales en algunas Comunidades Autónomas, así como para ampliarlo con un análisis más pormenorizado de las pruebas conducentes a puestos de intérprete-traductor en plantilla en distintas administraciones públicas. Si bien estos sistemas de acreditación están abiertos a múltiples perfiles lingüísticos, en el caso que nos ocupa se tomarán como punto de referencia las pruebas en la combinación inglés-español (salvo en el caso del sistema de Cataluña - TIJCATo8donde la combinación de partida es catalán/ inglés)5. Concretamente, se han analizado los sistemas de acreditación reflejados en la tabla r.

Para facilitar el análisis de los distintos procedimientos de acreditación objeto del presente estudio, se han confeccionado sendos cuadros

5 La Xunta de Galicia también cuenta con su propio sistema de acreditación de traductores e intérpretes jurados. Este autor no ha podido acceder a las pruebas planteadas, si bien la estructura general del sistema es exactamente igual que el de Cataluña. En el País Vasco, el sistema, ya aprobado, está pendiente de desarrollo. (cf. tabla 2 para la acreditación como intérprete y/o traductor jurado; $c f$. tabla 3 para la acreditación como intérprete-traductor en plantilla), a través de los cuales el lector podrá apreciar los rasgos característicos de los mismos.

Conviene tener en cuenta, no obstante, que en los distintos sistemas de acreditación analizados se han realizado pruebas para idiomas muy dispares, lo que responde tanto a las particularidades de cada uno de estos sistemas como a la demanda social en un momento dado; además, en el caso de las pruebas para puestos en plantilla es habitual que se exijan al candidato combinaciones lingüísticas formadas no ya sólo por uno, sino por dos, tres e incluso cuatro lenguas extranjeras en combinación con el castellano, por lo que conviene destacar que, en tal caso, en el sistema de acreditación se incluyen tantas pruebas de idioma como combinaciones lingüísticas se exijan al candidato. Para este trabajo, la estructura general del sistema de acreditación se presentará suponiendo que al candidato solamente se le exige una lengua extranjera, en este caso inglés, en combinación con castellano. 


\section{TABla 2: CoMparación ACREDITACIONES INTÉRPRETES-TRADUCTORES JURADOS}

\begin{tabular}{|c|c|c|c|c|}
\hline \multirow{2}{*}{\multicolumn{2}{|c|}{\begin{tabular}{|l|} 
PRUEBA \\
Titulación de acceso \\
\end{tabular}}} & \multirow{2}{*}{\multicolumn{2}{|c|}{$\mid$\begin{tabular}{|c|} 
IJMAECO \\
Diplomatura universitaria o eq
\end{tabular}}} & \multirow{3}{*}{$\begin{array}{c}\text { TIJCATO8 } \\
\text { Diplomatura universitaria o equivalente } \\
\end{array}$} \\
\hline & & & & \\
\hline \multirow{4}{*}{ 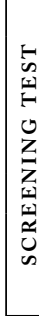 } & Duración & \multirow{4}{*}{\multicolumn{2}{|c|}{ Prueba escrita I y 2}} & \\
\hline & Descripción & & & $\begin{array}{l}\text { a) Batería de } 40 \text { preguntas elección múltiple } \\
\text { (3 opciones) sobre derecho } \\
\text { b) Batería de } 40 \text { oreguntas elección múltiple } \\
\text { (4 opciones) sobre lengua catalana }\end{array}$ \\
\hline & \% prueba & & & Eliminatoria /umbral de superación: 30 preguntas \\
\hline & Observaciones & & & $\begin{array}{l}\text { Existe la posibilidad de exención de estas prue- } \\
\text { bas (estar en posesión de determinadas cualifica- } \\
\text { ciones en Derecho y lengua Catalana) }\end{array}$ \\
\hline \multirow{12}{*}{ 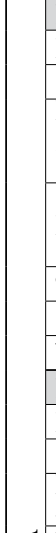 } & Prueba I & \multicolumn{2}{|l|}{ Traducción inglés > español } & Traducción inglés > catalán \\
\hline & Duración & \multicolumn{2}{|l|}{ I hora } & 3 horas \\
\hline & Extensión & 406 palabras & 357 palabras aprox. & 500 palabras aprox. \\
\hline & $\begin{array}{l}\text { Densidad léxica } \\
\text { media por frase } \\
\text { (mín/máx) }\end{array}$ & $22,5(2 / 4 \mathrm{I})$ & $\begin{array}{l}\text { No disponible } \\
\text { (N/D) }\end{array}$ & $\mathrm{N} / \mathrm{D}$ \\
\hline & Descripción & $\begin{array}{l}\text { Artículo de opinión sobre } \\
\text { la política policial antite- } \\
\text { rrorista de Gordon Brown }\end{array}$ & $\begin{array}{l}\text { Artículo de opinión } \\
\text { sobre las nuevas for- } \\
\text { mas de periodismo }\end{array}$ & Contrato «Exhibition Contract» \\
\hline & $\%$ prueba & Eliminatorio & & $55 \%$ \\
\hline & Encargo conocido & NO & & $\mathrm{NO}$ \\
\hline & Uso diccionarios & $\mathrm{NO}$ & & Sí (sólo en papel) \\
\hline & Prueba 2 & Traducción Español > Ing & lés & Traducción Catalán > Inglés \\
\hline & Duración & I hora & & 2 horas \\
\hline & Extensión & 362 palabras & 380 palabras & 300 palabras aprox. \\
\hline & $\begin{array}{l}\text { Densidad léxica media } \\
\text { porfrase (mín/máx) }\end{array}$ & $21,7(6 / 47)$ & $27, \mathrm{I}(3 / 64)$ & N/D \\
\hline \multirow[t]{12}{*}{ 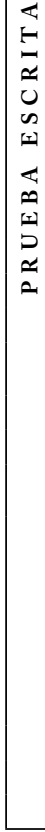 } & Descripción & $\begin{array}{l}\text { Artículo de prensa sobre } \\
\text { política medioambiental } \\
\text { europea }\end{array}$ & $\begin{array}{l}\text { Artículo de prensa } \\
\text { sobre costes labo- } \\
\text { rales }\end{array}$ & $\begin{array}{l}\text { Extracto de artículo periodístico sobre mujeres } \\
\text { emprendedoras. } \\
\text { Editorial sobre identidad cultural catalana } \\
\text { Extracto de un artículo de opinión sobre la } \\
\text { inconstitucionalidad de las leyes. } \\
\text { Extracto de la escritura notarial de constitu- } \\
\text { ción de una sociedad cooperativa catalana } \\
\text { limitada. }\end{array}$ \\
\hline & $\%$ prueba & \multicolumn{2}{|l|}{ Eliminatorio } & $35 \%$ \\
\hline & Encargo conocido & \multicolumn{2}{|l|}{$\mathrm{NO}$} & NO \\
\hline & Uso diccionarios & \multicolumn{2}{|l|}{$\begin{array}{ll}\mathrm{NO} \\
\mathrm{T}\end{array}$} & SÍ (sólo en papel) \\
\hline & Prueba 3 & \multicolumn{2}{|c|}{ Traducción Inglés > Español } & $\begin{array}{l}\text { Preguntas sobre cuestiones lingüísticas de los } \\
\text { textos traducidos }\end{array}$ \\
\hline & Duración & \multicolumn{2}{|l|}{ I hora 30 minutos } & Dentro del tiempo destinado a cada traducción \\
\hline & \multirow{2}{*}{\begin{tabular}{|l|} 
Extensión \\
$\begin{array}{l}\text { Densidad léxica media } \\
\text { por frase (mín/máx) }\end{array}$ \\
\end{tabular}} & 515 palabras & 504 palabras & No pertinente (N/A) \\
\hline & & $20,6(4 / 50)$ & I7 (8 / I45) & N/A \\
\hline & Descripción & \begin{tabular}{|l|} 
Extracto repertorio \\
jurisprudencia EE.UU. \\
«Logan, James v. U.S., \\
appealed from 7th U.S. \\
Circuit Court of Appeals \\
(July 6, 2006)» \\
\end{tabular} & $\begin{array}{l}\text { Extracto del informe } \\
\text { de Lord Justice } \\
\text { Auld «Review of the } \\
\text { Criminal Courts of } \\
\text { England and Wales- } \\
\text { Chapter Io: Preparing } \\
\text { for trial: Disclosure» }\end{array}$ & $\begin{array}{l}\text { En los textos se marcan algunas unidades/ } \\
\text { términos, etc. y se formulan preguntas sobre los } \\
\text { mismos. Ejemplo: } \\
\text { Anglès: Argumenteu la vostra proposta de traduc- } \\
\text { ció de la sigla RSPCA (The Royal Society for the } \\
\text { Prevention of Cruelty to Animals). }\end{array}$ \\
\hline & $\%$ prueba & \multicolumn{2}{|l|}{ Eliminatorio } & $10 \%$ \\
\hline & Encargo conocido & \multicolumn{2}{|l|}{$\mathrm{NO}$} & N/A \\
\hline & Uso diccionarios & \multicolumn{2}{|l|}{ SÍ (en papel) } & N/A \\
\hline
\end{tabular}


TAbla 2 (cont.)

\begin{tabular}{|c|c|c|c|}
\hline \multirow{2}{*}{\multicolumn{2}{|c|}{\begin{tabular}{|l|} 
PRUEBA \\
Titulación de acceso \\
\end{tabular}}} & \multirow{2}{*}{\begin{tabular}{c|r} 
IJMAECO & IJMAECO8 \\
matura universitaria o equivalente \\
\end{tabular}} & \multirow[b]{3}{*}{\begin{tabular}{|l}
\multicolumn{1}{|c}{ TIJCATo8 } \\
Diplomatura universitaria o equivalente \\
Disponibles en la Web oficial. \\
Del text traduitt s'avaluaran els aspectes següents: \\
Traducción directa \\
- La correcció lingüística: (màxim de 8 errors) \\
- La traducció: (recollir el contingut i la intenció del \\
text original, però no necessàriament mot a mot). \\
Traducción inversa \\
- La correcció lingüistica. \\
- La traducció. \\
- Els aspectes textuals: coherència, cohesió, adequa- \\
ció al registre i adequació a la funció comunica- \\
tiva del TO. \\
Se facilita igualmente una tipología de erro- \\
res de TeI juradas.
\end{tabular}} \\
\hline & & & \\
\hline & $\begin{array}{l}\text { Criterios de correc- } \\
\text { ción generales }\end{array}$ & No disponibles públicamente para el candidato & \\
\hline & $\begin{array}{l}\text { Preparación previa } \\
\text { examen }\end{array}$ & $\begin{array}{l}\text { Posibilidad de acceso a textos de convocatorias } \\
\text { anteriores previa solicitud a OIL }\end{array}$ & $\begin{array}{l}\text { Posibilidad de acceso a modelos de textos a través } \\
\text { de la Web oficial (http://www.gencat.cat/llengua) }\end{array}$ \\
\hline & $\begin{array}{l}\text { Umbral de supera- } \\
\text { ción global }\end{array}$ & N/A & $60 \%$ \\
\hline \multirow{7}{*}{ 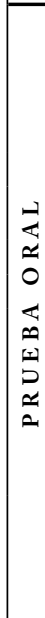 } & Descripción & $\begin{array}{l}\text { Resumen oral (en LT) de texto escrito (en } \\
\text { castellano) y comentarlo respondiendo a las } \\
\text { preguntas que se formulen al candidato }\end{array}$ & $\begin{array}{l}\text { Interpretación consecutiva dialógica de un frag- } \\
\text { mento de una conversación entre un juez, fiscal } \\
\text { o abogado y un testigo o acusado en una vista } \\
\text { oral o en una declaración. Discurso original en } \\
\text { vídeo - se graba al candidato en cassette. }\end{array}$ \\
\hline & Duración & N/A & I5 minutos \\
\hline & Densidad de produc- & N/A & No consta \\
\hline & $\%$ prueba & Eliminatoria & Al tratarse de acreditaciones diferenciadas N/A \\
\hline & Encargo conocido & N/A & NO \\
\hline & $\begin{array}{l}\text { Criterios de eva- } \\
\text { luación }\end{array}$ & No disponibles públicamente para el candidato & $\begin{array}{l}\text { El umbral de superación de la prueba es 6I\% } \\
\text { Se evalúan tres componentes: } \\
\text { - Dominio de las técnicas de interpretación } \\
\text { (comprensión y reformulación) } 40 \% \\
\text { - Nivel de lengua catalana 30\% } \\
\text { - Nivel de lengua de llegada 30\% }\end{array}$ \\
\hline & Observaciones & & $\begin{array}{l}\text { SE TRATA DE ACREDITACIONES DIFERENCIADAS: } \\
\text { TRADUCTOR VS. INTÉRPRTE. Puede haber } \\
\text { candidatos que únicamente soliciten una acre- } \\
\text { ditación o ambas. }\end{array}$ \\
\hline
\end{tabular}

\section{Acreditación de traductores e intérpretes jurados: análisis comparativo}

En la tabla 2 se presenta de forma esquemática la estructura de las pruebas conducentes al nombramiento como intérprete jurado del MAEC y como traductor o intérprete jurado de la Generalitat de Cataluña. Para facilitar la comparación entre ambos sistemas, las distintas pruebas y ejercicios se han distribuido en tres grandes bloques que corresponden a las partes que suelen presentar algunos de los modelos de acreditación internacional analizados en trabajos anteriores (Ortega Herráez, 20II): prueba inicial eliminatoria (screening test), prueba escrita y prueba oral. En el caso concreto de los ejercicios de traducción se especifican aspectos relativos al texto objeto de examen (direccionalidad, extensión, densi- 
dad léxica media por frase, temática) como a las propias condiciones de examen (duración, encargo previo conocido, si está permitido el uso de material de consulta).

Según lo recogido en la tabla 2 las diferencias entre los dos sistemas de acreditación de intérpretes jurados son más que patentes. A continuación se presentan las principales diferencias apreciadas.

\section{Evaluación de la competencia en interpretación.}

Habida cuenta de la propia denominación profesional (intérprete jurado ${ }^{6}$ ) llama poderosamente la atención el hecho de que entre las pruebas del MAEC no se evalúe la competencia en interpretación de los candidatos y sólo se recurra a una prueba oral cuyo objetivo parece ser únicamente medir la capacidad comunicativa en lengua extranjera. Si bien es cierto que tradicionalmente los profesionales que ostentan esta acreditación han venido dedicándose mayoritariamente al ejercicio de la traducción «sobre el papel están capacitados para el ejercicio de ambas profesiones», como apunta Mayoral (2000 I22).

De hecho, ante las diferencias existentes entre traducción e interpretación, no podemos sino coincidir con las críticas vertidas por García-Medall (1998: 68) quien afirma que «una competencia comunicativa alta en una $\mathrm{L}_{2}$ facilita, pero no garantiza, una competencia en la interpretación de una L2». También coincidimos con Way (2005: 258) cuando se pregunta «jen qué se asemeja la cuarta prueba al trabajo oral del intérprete jurado? ¿De qué clase de textos se trata?».

6 Como ya se ha mencionado hasta la modificación de la normativa correspondiente en diciembre de 2009 la denominación oficial ha sido "intérprete jurado", y en la actualidad es "traductor-intérprete jurado".
Prueba de este carácter diferenciado entre ambas actividades es el hecho de que en su sistema de acreditación la Generalitat de Cataluña decidiera, además de incluir una prueba de interpretación consecutiva dialógica, separar claramente la acreditación de traductor y la de intérprete. En la Web oficial de la Generalitat se puede acceder a un ejemplo de prueba oral y a extractos en vídeo de las pruebas de inglés, francés y castellano ${ }^{7}$ de la convocatoria de 1999. Según Salvador (2007: 27) la estructura de la prueba se acordó entre representantes de la Generalitat e integrantes de las tres facultades de traducción e interpretación existentes en Cataluña ${ }^{8}$. En las pruebas orales se intentan simular casos verosímiles de declaraciones por robos o conflictos diversos. Los candidatos han de interpretar a partir de la grabación en video de la simulación. Así, tras el parlamento de cada personaje cuen$\tan$ con un hueco suficiente para insertar sus traducciones; cabe añadir que los candidatos pueden visionar completamente el vídeo una vez antes de pasar a realizar la interpretación, lo que sin duda se alejaría de una situación real de trabajo. A partir del análisis del texto que se presenta como ejemplo en la Web oficial se pueden realizar una serie de apreciaciones sobre algunas cuestiones que han llamado la atención de este autor.

En primer lugar, en este ejemplo se simula una toma de declaración en la que un fiscal interroga a un acusado que no habla la lengua oficial del procedimiento (en este caso catalán); de entrada, este tipo de situaciones no se nos

\footnotetext{
7 http://www.gencat.cat/llengua

8 Por parte de la Generalitat: la Escuela de Administración Pública de Cataluña y la Escuela Oficial de Idiomas. Además, las tres facultades de traducción e interpretación de Cataluña: Pompeu Fabra, Autónoma de Barcelona y Vic.
} 
antojan muy comunes (el que un fiscal dirija el interrogatorio). El interrogatorio comienza con el fiscal pidiendo al intérprete que informe al acusado de los derechos que le asisten y según el guión propuesto, parece que se espera que sea el propio intérprete el que motu proprio comunique los derechos al detenido, tomando así una iniciativa que quizá no le corresponde conforme a lo que suelen disponer los códigos de conducta existentes en otros países:

$\overline{\text { EL FISCAL, (adreçant-se a l'intèrpret): Llegeixi-li els }}$ seus drets.

L'INTÈRPRET, (dirigint-se a l'acusat): Té dret a guardar silenci. totes les declaracions que faci poden ser utilitzades en contra seu. Té dret a ser assistit per un advocat que designi o per un d'ofici. Té dret que es comuniqui al consolat del seu país el fet de la seva detenció i el lloc on es troba retingut. Té dret a ser assistit gratuïtament per un intèrpret. Té dret a ser reconegut per un metge forense.

De la misma forma, la situación procede de forma poco convencional, pues el acusado no es informado en ningún momento de la causa de su detención. En este caso la simulación se centra fundamentalmente en cuestiones relacionadas con hechos y hay una relativa menor presencia de terminología y fraseología jurídico-administrativa que, en este caso, está relacionada fundamentalmente con trámites de inmigración. Por su parte, la mayoría de los parlamentos tienen una extensión muy asequible. A pesar de esta aparente sencillez, según se ha podido saber a través de una de las integrantes del tribunal evaluador, sólo aquellos candidatos que cuentan con sólidas destrezas en técnicas de interpretación son capaces de superar la prueba9:

9 Información obtenida mediante comunicación personal por correo electrónico con D. ${ }^{\text {a }}$ Xus Ugarte, profesora de interpretación de la Universidad de Vic, en noviembre de 2009 .
FISCAL: On és la seva documentació $i$ els visats d'entrada obtinguts en el seu país?

ACUSAT: I don't have a visa, I didn't think it was necessary to apply for one. A friend told me I could get a job here. I come from a country where people are not free and I was persecuted for my political ideas. Here people are free and I want to work for a better future for me and my family.

En todo caso, el análisis del ejemplo propuesto y de los vídeos de convocatorias anteriores muestra que en estos diálogos no se presta una especial atención a incluir parlamentos con información de carácter procesal que sí es habitual en una situación real de trabajo y que quizá sería interesante evaluar. De hecho, se aprecia una clara asimetría en términos de presencia de lenguaje jurídico entre la prueba oral y las pruebas de traducción, extremo que también nos ha sido confirmado por las fuentes consultadas. Así las cosas, tras este sencillo análisis de la prueba de interpretación cabría plantearse si, en su configuración actual, es suficiente para otorgar la acreditación profesional en cuestión o si, por el contrario, necesitaría verse complementada por otros ejercicios (interpretación susurrada, traducción a vista, etc.) e incluso presentase situaciones verdaderamente basadas en la realidad, ajustándose al parámetro de autenticidad propugnado desde la bibliografía analizada (cf. Hewitt, I995: I02).

\section{Evaluación de la competencia traductora: marco general de las pruebas.}

Salvo el caso de la Generalitat, el núcleo central de las pruebas de acreditación lo constituyen ejercicios de traducción. En términos generales vemos nuevamente cómo el sistema del MAEC difiere del de la Generalitat en aspectos como la información previa sobre las pruebas, el acceso a documentación durante el examen, el acceso a criterios de evaluación, etc. Desafortunada- 
mente, a tenor de lo visto en la tabla 2, lo manifestado, entre otros, por Way (2005: 258), sigue siendo aplicable a las pruebas de intérprete jurado del MAEC analizadas:

¿Cuándo traduce un intérprete jurado sin diccionario o sin preparación del tema a traducir o interpretar? ¿Qué proporción de su trabajo representan los textos periodísticos y literarios? ¿Por qué se admite el uso de diccionario en la tercera prueba (a menudo solamente monolingüe) y no de manuales o códigos de Derecho? ¿En cuantas oposiciones o concursos se presentan los candidatos sin temarios, sin baremos, y sin posibilidad de recurrir las decisiones del tribunal?

Esta situación contrasta con el sistema empleado en la Generalitat de Cataluña, donde las pruebas de acreditación profesional sí parecen seguir un patrón en cierta forma análogo al recomendado por Hewitt (1995). En primer lugar existe una prueba de tipo eliminatorio sobre contenidos lingüísticos y de conocimientos jurídicos (a partir de un temario bastante extenso, todo hay que decirlo) ( $c f$. Generalitat de Cataluña, 2000). En lo que a los conocimientos lingüísticos se refiere únicamente se miden en lengua oficial, y no en la lengua extranjera, con lo que quizá el objetivo mismo de todo screening test no se vea plenamente satisfecho. En lo que a las pruebas escritas se refiere se evidencia una transparencia mayor que en el caso del MAEC, ya que en este caso los candidatos sí tienen acceso a través de la Web oficial a modelos de examen (en el caso del MAEC los candidatos interesados han de solicitarlos personalmente a la Oficina de Interpretación de Lenguas - OIL-) y a los criterios generales de corrección (que en el MAEC no se facilitan), conocen de antemano el peso específico de cada prueba en el cómputo global, pueden emplear diccionarios en ambas pruebas, etc. Además, el tiempo de realización de cada prueba es muy superior al concedido en el MAEC si se compara la extensión de los textos propuestos en ambos sistemas.

\section{Evaluación de la competencia traductora:} textos utilizados

En lo que al análisis de los textos objeto de traducción se refiere, conviene destacar que en el caso del MAEC, al menos en el caso de las dos convocatorias analizadas, sí se han apreciado ligeras diferencias frente a lo recogido por Giambruno (1997: 240-244). Si bien el estudio de dicha autora se llevó a cabo con anterioridad a las reformas introducidas en 1996, el análisis lingǘstico de los textos arrojó como resultado grandes disparidades en términos de longitud de los textos, longitud media de las frases, densidad léxica y estructural, nivel de dificultad, así como variedad estilística y temática, hasta el punto de llegar a afirmar que «regardless of the purpose of each exercise, it would appear that care was not taken to ensure equivalency from one exam session to the next, and it is reasonable to think that the same candidate sitting for different versions of the exam could produce very different results» (Giambruno, 1997: 243).

Como se puede ver en la tabla 2, en las convocatorias de 2007 y 2008 la temática de los textos era análoga, la extensión de los mismos se puede considerar equiparable (salvo quizás en el primer ejercicio) y es quizá la propia tipología textual la que arroja diferencias en términos de extensión media de las frases en el caso del tercer ejercicio. En lo que a la densidad terminológica se refiere, esta viene dada no tanto por el grado de repetición de términos sino por la propia extensión del texto y su naturaleza (de carácter más bien «general» o marcadamente especializado). Así, en un sencillo análisis realizado con Wordsmith para comprobar el grado de repetición terminológica que presentan los 
textos, se puede apreciar un grado de repetición relativamente bajo (con apenas dos o tres términos con más de tres apariciones en cada texto), tanto en los ejercicios de directa como de inversa.

No obstante, si se comparan los ejercicios de inglés con los planteados para otros idiomas (ver tabla 4), se aprecian algunas diferencias en términos de tipología textual y temática tratada para cada ejercicio, lo que sin duda podría arrojar diferencias en cuanto a la densidad léxica, sintáctica y terminológica. Esto nos hace pensar que quizá el desarrollo de las pruebas no es homogéneo y consistente para todas las combinaciones lingüísticas y quizá la aparente consistencia en las pruebas de inglés analizadas obedezcan a que los textos han sido elegidos por una misma persona o equipo de personas. De hecho, Giambruno (1997: 247) constató claras divergencias entre las pruebas de idiomas mayoritarios (inglés, francés y alemán; en los que tradicionalmente hay muchos más candidatos) y las de lenguas de difusión más limitada. Sería pues interesante profundizar en este análisis y recabar la opinión del propio MAEC, extremo que según manifiestan los autores citados no suele ser fácil.

Por su parte, en las pruebas conducentes al nombramiento como traductor jurado de catalán las tipologías textuales parecen ajustarse mejor a lo que quizá el mercado profesional espera del traductor jurado. En el caso de la prueba de traducción directa los textos son de naturaleza jurídica en todos los idiomas ( $c f$. tabla 2), si bien desconocemos si en cada convocatoria se optaría por el mismo género textual para todos, lo cual reviste gran importancia de cara a valorar la validez y consistencia interna del propio sistema. No obstante, a tenor de los distintos modelos de textos a los que se puede acceder para la segunda prueba, donde tienen cabida desde escrituras notariales a editoriales periodísticas sobre identidad cultural catalana, cabría preguntarse si realmente los responsables de este sistema de acreditación aplican criterios de validez, autenticidad y consistencia entre convocatorias y entre combinaciones lingüísticas.

\section{Acreditación de traductores e intérpretes jurídicos en plantilla: análisis comparativo}

A continuación se presenta de forma comparada las pruebas de acreditación empleadas en el Ministerio de Justicia, el Ministerio del Interior y la Junta de Andalucía. Para facilitar la comparación se he elaborado un cuadro resumen (tabla 3 ) siguiendo los criterios empleados en la sección anterior.

En el caso de las acreditaciones como intérprete-traductor judicial y policial en plantilla analizadas existen claras diferencias con las acreditaciones como traductor jurado, fundamentalmente derivadas del nivel de cualificación académica exigida para acceder al sistema, lo que sin duda parece condicionar la tipología textual que se emplea en las pruebas o la dificultad de los textos empleados. No obstante, en ambos casos se aprecian deficiencias en términos de validez, fiabilidad y comparabilidad de los propios instrumentos de medida, habida cuenta de la falta de transparencia sobre aspectos clave como los criterios de evaluación, forma en que se desarrollan las pruebas, idoneidad de las mismas, etc. A continuación presentamos los principales resultados que arroja el análisis comparativo de las pruebas.

\section{Evaluación de la competencia en interpretación}

En primer lugar cabe destacar nuevamente la ausencia generalizada de una prueba que mida la competencia en interpretación de los candi- 
TавLA 3. Comparación acreditaciones intérpretes-traductores jurídicos en plantilla

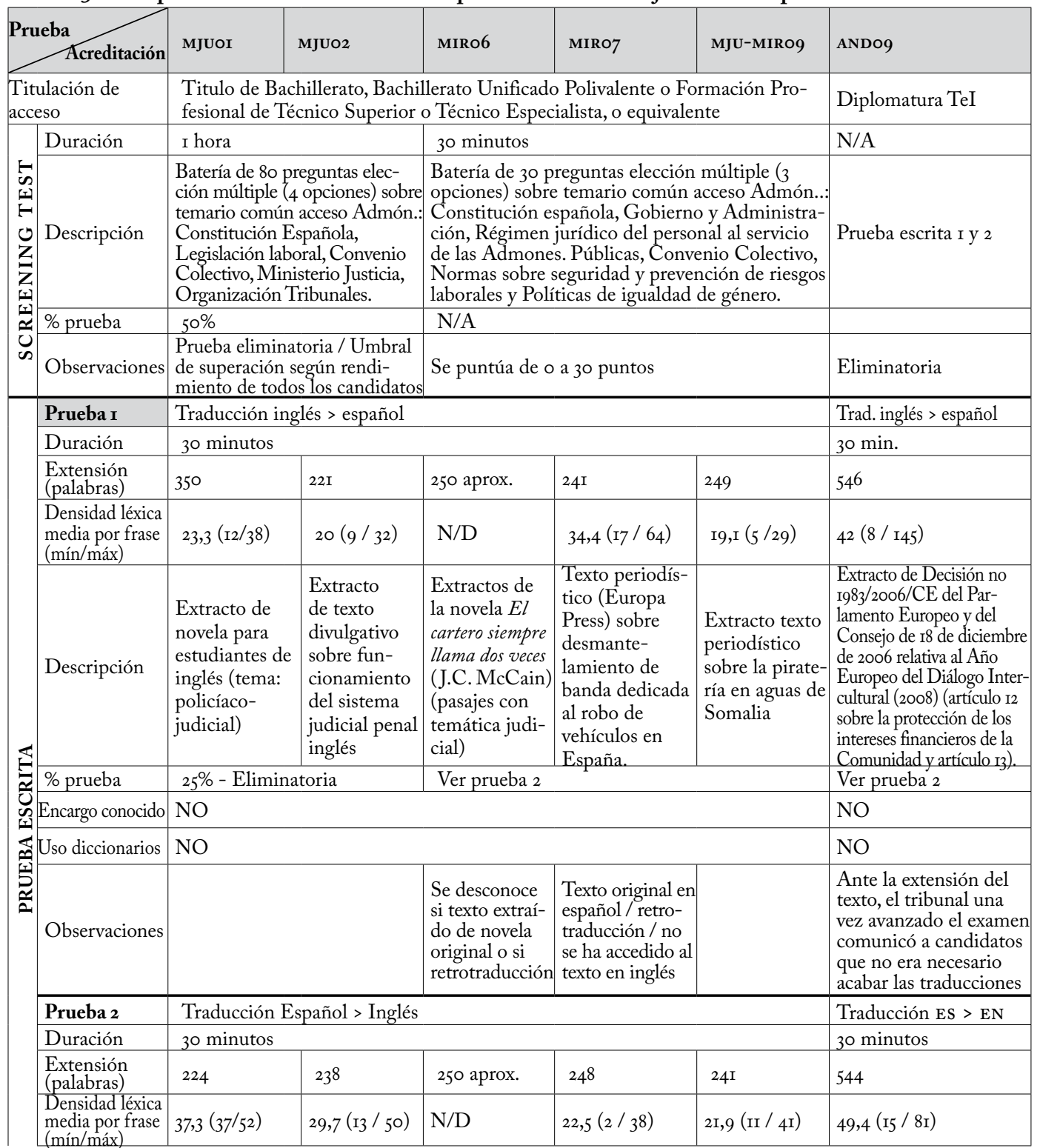

\begin{tabular}{|c|c|c|c|c|c|c|}
\hline Descripción & $\begin{array}{l}\text { Noticia de } \\
\text { prensa: crónica } \\
\text { judicial }\end{array}$ & \begin{tabular}{|l|} 
Noticia de \\
prensa: cró- \\
nica judicial \\
(implantación \\
de juicios \\
rápidos)
\end{tabular} & \begin{tabular}{|l|} 
Extractos de la \\
novela El cartero \\
siempre llama \\
dos veces (J.C. \\
McCain) (pasa- \\
jes con temática \\
judicial)
\end{tabular} & $\begin{array}{l}\text { Noticia de } \\
\text { prensa: inmi- } \\
\text { gración y mer- } \\
\text { cado laboral }\end{array}$ & $\begin{array}{l}\text { Extracto de } \\
\text { nota informativa } \\
\text { para turistas de } \\
\text { la embajada de } \\
\text { EEUU en Espa- } \\
\text { ña sobre carte- } \\
\text { ristas y timos }\end{array}$ & $\begin{array}{l}\text { Síntesis del Informe } \\
\text { anual } 2006 \text { sobre Dere- } \\
\text { chos Humanos del } \\
\text { Parlamento Europeo. }\end{array}$ \\
\hline
\end{tabular}


TABLA 3. (CONT.)

\begin{tabular}{|c|c|c|c|c|c|c|c|}
\hline \multicolumn{2}{|c|}{ Prueba } & MJUOI & MJUO2 & MIRo6 & MIRO7 & MJU-MIRO9 & ANDO9 \\
\hline & $\%$ prueba & \multicolumn{2}{|c|}{$25 \%$ - Eliminatorio } & \multicolumn{3}{|c|}{$\begin{array}{l}\text { Ambas pruebas de traducción se puntúan de } \\
\text { o a } 70 \text { puntos }\end{array}$} & Eliminatoria \\
\hline & Encargo conocido & \multicolumn{5}{|l|}{$\mathrm{NO}$} & NO \\
\hline & Uso diccionarios & \multicolumn{5}{|l|}{$\mathrm{NO}$} & $\mathrm{NO}$ \\
\hline & \multirow[b]{2}{*}{ 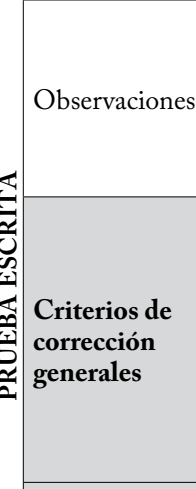 } & & & $\begin{array}{l}\text { Retrotr } \\
\text { ción }\end{array}$ & & $\begin{array}{l}\text { Retrotraduc- } \\
\text { ción }\end{array}$ & $\begin{array}{l}\text { Ante la extensión del } \\
\text { texto, el tribunal una } \\
\text { vez avanzado el examen } \\
\text { comunicó a candidatos } \\
\text { que no era necesario aca- } \\
\text { bar las traducciones } \\
\end{array}$ \\
\hline & & \multicolumn{3}{|c|}{$\begin{array}{l}\text { No disponibles públicamente para el } \\
\text { candidato }\end{array}$} & \multicolumn{3}{|c|}{$\begin{array}{l}\text { ANDALUCía: En cuadernillo de examen se especifican: } \\
\text { 60\%: traducción (correcta resolución de problemas, preci- } \\
\text { sión uso terminología, uso de procedimientos técnicos adecua- } \\
\text { dos (trad. literal v. trad. oblicua) [sic], ausencia contradiccio- } \\
\text { nes; se valorará esfuerzo por conseguir equivalencia pertinente } \\
\text { según el enfoque (adecuada o aceptable)). } \\
\text { 40\%: uso de la lengua de llegada (naturalidad, correcta } \\
\text { expresión escrita, ausencia de espacios en blanco, coherencia } \\
\text { discursiva, faltas de ortografía y puntuación) } \\
\text {-o,20 puntos por error }\end{array}$} \\
\hline & $\begin{array}{l}\text { Preparación } \\
\text { previa }\end{array}$ & \multicolumn{5}{|c|}{ No se puede acceder oficialmente a textos de otras convocatorias } & N/A \\
\hline & $\begin{array}{l}\text { Umbral de } \\
\text { superación } \\
\text { global de la } \\
\text { prueba escrita }\end{array}$ & $\begin{array}{l}\text { ElTribu } \\
\text { número } \\
\text { to de los } \\
\text { nará la n } \\
\text { para sup } \\
\text { haciendo }\end{array}$ & $\begin{array}{l}\text { la vista del } \\
\text { el de conocimien- } \\
\text { rantes determi- } \\
\text { nínima requerida } \\
\text { os ejercicios, } \\
\text { lico el acuerdo o }\end{array}$ & Ver pru & a oral & & Ver prueba oral \\
\hline \multirow{5}{*}{ 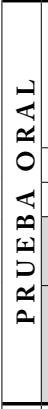 } & Descripción & \multirow{5}{*}{\multicolumn{2}{|c|}{ N/A }} & $\begin{array}{l}\text { Lectura } \\
\text { tribuna }\end{array}$ & le pruebas escritas ante & $\begin{array}{l}\text { Lectura de } \\
\text { pruebas escritas } \\
\text { ante tribunal } \\
\text { y conversación } \\
\text { con el tribunal }\end{array}$ & $\begin{array}{l}\text { Desarrollo de un tema } \\
\text { oralmente (sin cono- } \\
\text { cimiento previo del } \\
\text { mismo) y entrevista } \\
\text { con el tribunal }\end{array}$ \\
\hline & Duración & & & Io $\mathrm{min}$ & & & I5 minutos \\
\hline & $\%$ prueba & & & N/A & & & N/A \\
\hline & $\begin{array}{l}\text { Criterios de } \\
\text { evaluación }\end{array}$ & & & $\begin{array}{l}\text { No dis } \\
\text { dato }\end{array}$ & onibles públicamente pa & ara el candi- & $\begin{array}{l}\text { No disponibles públi- } \\
\text { camente }\end{array}$ \\
\hline & $\begin{array}{l}\text { Observacio- } \\
\text { nes }\end{array}$ & & & $\begin{array}{l}\text { Ambas } \\
\text { supera } \\
\text { prueba }\end{array}$ & $\begin{array}{l}\text { ruebas de o a } 70 \text { puntos } \\
\text { ón: suma de screening, pr } \\
\text { ral sea, como mínimo, d }\end{array}$ & $\begin{array}{l}\text { s. Umbral de } \\
\text { rueba escrita y } \\
\text { de } 50 \text { puntos. }\end{array}$ & $\begin{array}{l}\text { Ambas pruebas de o a } \\
\text { IIo puntos, umbral 55. } \\
\text { A prueba oral sólo los } \\
\text { aptos en traducciones. }\end{array}$ \\
\hline \multirow{2}{*}{ 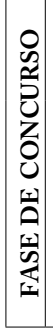 } & \multirow[b]{2}{*}{ Baremo } & \multirow{2}{*}{\multicolumn{2}{|c|}{$\begin{array}{l}\text { Entre los que consiguen } \\
\text { plaza, para establecer orden } \\
\text { de prelación }\end{array}$}} & \multicolumn{4}{|c|}{$\begin{array}{l}\text { A la fase de concurso acceden los candidatos que hayan superado las } \\
\text { pruebas y la nota final se calculará sumando la nota de la fase de oposi- } \\
\text { ción y la del concurso. }\end{array}$} \\
\hline & & & & $\begin{array}{l}33 \text { pun } \\
\text { tos aca }\end{array}$ & $\begin{array}{l}\text { s: } 30 \text { méritos profesiona } \\
\text { émicos }\end{array}$ & ales y 3 méri- & $\begin{array}{l}\text { 9o puntos: } 45 \text { expe- } \\
\text { riencia profesional, } \\
\text { I5 antigüedad en la } \\
\text { Addmón., Io cursos de } \\
\text { perfeccionamiento, Io } \\
\text { docencia cursos perfec- } \\
\text { cionamiento, Io titula- } \\
\text { ciones académicas }\end{array}$ \\
\hline
\end{tabular}


datos. En este caso se trata de un aspecto preocupante habida cuenta de que, a diferencia de los traductores jurados, en el ámbito judicial y policial una proporción considerable del trabajo consiste en interpretar en situaciones diversas. Es más, en algunas combinaciones lingüísticas, como puede ser el árabe, la interpretación puede llegar a suponer más del 90\% del total de la actividad laboral. $\mathrm{Ni}$ que decir tiene que la ausencia de una prueba formal de interpretación invalida totalmente el proceso de selección de intérpretes. Pero lo mismo cabría decir de aquellas pruebas que bajo la apariencia de una prueba oral en formato entrevista esconden una mera lectura en voz alta de un texto, ya que dudamos del verdadero objetivo de la misma y de su capacidad para valorar correctamente la capacidad comunicativa en $\mathrm{L}_{2}$, y menos aún en interpretación.

\section{Evaluación de la competencia traductora: marco general de las pruebas}

En lo que a las pruebas escritas se refiere, en el caso de las convocatorias del Ministerio de Justicia, Ministerio del Interior y Ministerio de Administraciones Públicas (para puestos en el Ministerio de Justicia y/o Interior) se incluye una prueba sobre conocimientos temáticos que no siempre se puede considerar como screening dado su carácter no eliminatorio. $\mathrm{Si}$ bien con el paso del tiempo se aprecian modificaciones en la estructura y características de las distintas pruebas, lo cierto es que todas ellas se ajustan estructuralmente al tipo de pruebas de acceso empleadas por la administración española para el personal laboral. Cabe, pues, preguntarse si las pruebas temáticas, por los contenidos evaluados, son realmente útiles o necesarias para el futuro profesional del intérprete-traductor. De hecho, en el caso de la Junta de Andalucía se prescinde de ese tipo de prueba. Pero no menos importante es el hecho de que en algunos casos, sobre todo en los que la prueba no tiene carácter eliminatorio, la misma está sobrevalorada frente a los ejercicios de traducción.

Cabe reseñar también que, en función del tipo de convocatoria, es posible que tras la fase de oposición (es decir, la fase que contiene las pruebas) haya una fase de concurso en la que los candidatos reciben una serie de puntos sobre la base de determinados méritos profesionales y académicos. Estos baremos tienden a sobrevalorar la experiencia profesional adquirida en el propio puesto al que se opta, la puntuación por formación continua sólo contempla la ofrecida por la administración a su propio personal y la puntuación por contar con titulación específica o superior a la exigida es testimonial en el cómputo global. Sin lugar a dudas todo esto introduce en el proceso de selección-acreditación un elemento distorsionador que perjudica especialmente a aquellos candidatos que no han tenido la oportunidad de trabajar previamente para la administración.

\section{Evaluación de la competencia traductora: textos utilizados}

En las pruebas escritas de traducción se aprecian claras diferencias en lo que a la extensión de los textos se refiere, lo cual evidencia la falta de criterios objetivos en el desarrollo de las mismas. Así, en las convocatorias del MIR y del MJU, contamos con textos que van de las 220 palabras a las 545 palabras, todos para traducir en el mismo tiempo. No obstante, parece que en las últimas convocatorias, tanto para justicia como para ámbitos policiales, se ha llegado al criterio de presentar textos de una extensión aproximada de 250 palabras en los que la densidad léxica por oración (quizá 
por pura casualidad) se mueve dentro de unos márgenes similares. Evidentemente, en función de la extensión del texto los candidatos se encontrarán en mejores o peores condiciones para realizar su tarea dentro de las limitaciones de tiempo de las pruebas. Pero hay situaciones que son, a todas luces, desproporcionadas. Tal es el caso de la Junta de Andalucía, donde a tenor de las opiniones de varios candidatos a los que este autor tuvo acceso ${ }^{\mathrm{IO}}$, resultaba muy difícil traducir los textos propuestos, dada su extensión, en apenas 30 minutos. De hecho, según se ha podido constatar, una vez avanzado el examen, los miembros del tribunal comunicaron a los asistentes que habida cuenta de la excesiva extensión de los textos no se preocupasen por intentar acabarlos, lo que sin duda introduce una serie de elementos subjetivos en la evaluación que alejan el procedimiento de selección de cualquier sistema de acreditación serio y profesional y demuestra la aparente falta de conocimientos técnicos especializados en evaluación y en traducción de los integrantes del tribunal.

En lo que a la temática de los textos propuestos se refiere, podemos comprobar cómo, salvo en el caso de Andalucía, en la mayoría de los casos se proponen crónicas periodísticas que, en el mejor de los casos, versan sobre cuestiones relacionadas con la justicia, diligencias policiales o la inmigración. Vemos también cómo en alguna ocasión se han propuesto textos de corte literario. Esta aparente consistencia en el caso del inglés no se ve reflejada en las mismas convocatorias en otros pares de lenguas, donde en ocasiones se han propuesto textos realmente especializados como pueden

\footnotetext{
Io Información obtenida mediante comunicación telefónica personal con candidatos que se presentaron a las pruebas en octubre de 2009 . Por deseo expreso de estas personas no se incluyen sus datos de filiación.
}

ser extractos de sentencias de distinto tipo ( $c f$. tabla 4 ).

En el caso de Andalucía, a pesar del carácter especializado de los textos propuestos, estos no forman parte del conjunto de tipologías textuales con las que con mayor frecuencia habrá de enfrentarse un traductor e intérprete judicial. Se trata de textos más relacionados con el perfil de un traductor en organismos internacionales. Ni que decir tiene que la imposibilidad de usar diccionarios u otro tipo de recursos dificulta enormemente la tarea de los candidatos y no reflejará su capacidad para realizar una traducción conforme a parámetros profesionales.

El análisis de todos los textos con Wordsmith arroja conclusiones similares a las registradas en el caso de los exámenes de traductor jurado en cuanto a la repetición terminológica, siendo la excepción aquellos textos en los que relativamente hay una mayor repetición de los mismos términos. Además, estos términos son básicos dentro del ámbito de trabajo en el que se supone que tendrán que desempeñar su trabajo los candidatos que superen las pruebas: detenido, prisión incondicional, juez, guilty, jury o trial (MJUor); justicia, juicios rápidos, guilty, jury, court, evidence, judge, accused, case, crime, magistrates, trial, witness (MJUO2); detención, inmigrantes (MIRo6); denuncia, robo, víctima, pirates, ship (MJU-MIRog).

Cabe destacar también el hecho de que en ocasiones se empleen los mismos textos para todas las combinaciones lingüísticas, tanto en directa como en inversa. Para ello se recurre a la retrotraducción sistemática de algunos textos, con los problemas que, a nuestro juicio, esto puede plantear. Lo que nadie puede negar es que someter a todos los candidatos a la traducción de un mismo texto, a saber, un fragmento de El cartero siempre llama dos veces, supone pre- 
sentar textos carentes de referencias culturales y administrativas específicas, con una estilística quizá alejada de los cánones habituales de una lengua y cultura determinada, carentes de terminología especializada, etc. Habría, pues, que preguntarse qué es lo que realmente persiguen evaluar los examinadores con este tipo de pruebas, ya que es más que probable que un mayor número de candidatos estén en disposición de realizar una traducción que, desde un punto de vista meramente lingüístico, pueda parecer adecuada y sea realmente complicado discernir qué candidatos merecen realmente superar la prueba.

\section{Desarrollo y corrección de las prueba}

Conviene aquí mencionar cómo se organizan estos exámenes y quiénes participan en los tribunales de evaluación correspondientes. Por norma general, los tribunales evaluadores están integrados por funcionarios que representan a la Admón. y representantes sindicales y, en el mejor de los casos, entre ellos puede encontrarse -normalmente como vocal- algún integrante de la categoría profesional a la que optan los candidatos, en nuestro caso, traductores e intérpretes ya en plantilla. No obstante, estos miembros del tribunal, a lo sumo, podrán evaluar a los candidatos en alguno de los idiomas de sus lenguas de trabajo, por lo que habrá de recurrirse también a asesores lingüísticos externos a los que se encarga la preparación y corrección de las pruebas para el resto de idiomas. Los criterios de selección de estos asesores externos no están muy claros, si bien tradicionalmente se ha recurrido a profesorado de las Escuelas de Idiomas, personal de embajadas, etc., sin que nos conste que se recurra sistemáticamente a investigadores o profesores en traducción y/o interpretación, o a profesionales debidamente acreditados.
A la hora de seleccionar los textos objeto de examen, al menos en las convocatorias del MIR y MJU, la única indicación que reciben los asesores es que los textos no deben superar las 250 palabras (tal y como consta en las bases) y que los textos no aborden temáticas que se pudieran considerar «conflictivas» (desde un punto de vista político, religioso, ideológico, etc. $)^{\mathrm{II}}$. Además, según se ha podido saber, al menos en la convocatoria de 2009 del MIR-MJU se instó a los asesores a que eligieran textos lo suficientemente difíciles como para permitir identificar a los mejores candidatos y que los textos tuvieran una temática judicial o policial. Por norma general estos asesores han de presentar al tribunal distintos textos y será el tribunal el que decida qué texto será, finalmente, objeto de examen. Evidentemente, estas propuestas han de ir acompañadas de traducciones al español para que el tribunal sepa exactamente sobre qué versan los textos.

Llama también la atención el que en los exámenes analizados no se pueda acceder previamente a los criterios de corrección y evaluación. De hecho, según se ha podido saber para el caso de los exámenes organizados por la administración general del Estado (MIR, MAP, MJU) los asesores responsables de la selección de los textos y que, en última instancia, habrán de corregir los exámenes (a partir de la lectura en sesión pública ante el tribunal) no reciben ningún tipo de directriz sobre criterios de corrección. Así, en la práctica, se pueden aplicar criterios de corrección diferentes para cada par de lenguas. Igualmente peculiar resulta la

II Esta información ha sido obtenida y contrastada a través de comunicaciones personales telefónicas realizadas en octubre de 2009 con varias personas que en distintos momentos han formado parte de estos tribunales evaluadores. Por deseo expreso de estas personas no se incluyen sus datos de filiación. 
evaluación de las pruebas ya que el asesor, al no ser miembro del tribunal, no tiene realmente voto, por lo que su función se limita a indicar al tribunal si el candidato ha realizado o no un buen ejercicio y sugerir una puntuación; la puntuación final, en última instancia, resulta de la media resultante de la que individualmente cada integrante del tribunal (en la mayoría de los casos sin conocimientos específicos ni de traducción ni de las lenguas evaluadas) otorgue al candidato, lo que no deja de ser un hecho totalmente arbitrario e irregular a juicio de este autor. Nuevamente nos encontramos ante el hecho de que los candidatos, en función de sus combinaciones lingüísticas y sometidos al total albedrío del tribunal y sus asesores, pueden ser evaluados de forma diferente, lo que nos lleva a cuestionar la validez y fiabilidad del sistema de acreditación.

\section{CONCLUSIONES}

A tenor de lo que se ha venido exponiendo y analizando en el presente artículo, a continuación se presentan una serie de conclusiones generales en torno a las acreditaciones profesionales de traductores e intérpretes jurídicos en España, lo que dará paso a una reflexión acerca de las posibles medidas correctoras de cara al futuro.

\section{Inexistencia de evaluación de la competencia en interpretación}

A pesar de que todos los sistemas analizados tienen como objetivo la acreditación de profesionales que desempeñen tareas de interpretación en entornos jurídicos, salvo en un caso, ninguno cuenta entre sus pruebas con ejercicios específicos destinados a evaluar la competencia en interpretación de los candidatos. La interpretación es pues la gran olvidada, con las consecuencias que ello puede tener habida cuenta de que, especialmente en el caso de los puestos en plantilla, y para determinadas combinaciones lingüísticas, el grueso del trabajo se centrará en la interpretación (Ortega Herráez, 20Ir: 87). Vemos cómo de forma sistemática se considera que una mera prueba para verificar la competencia comunicativa en la lengua extranjera es suficiente para interpretar, lo cual se aleja bastante de la práctica habitual en los sistemas de acreditación internacional y de la realidad de los centros especializados en la formación de intérpretes.

Esta situación es claramente llamativa en el caso de la acreditación de intérpretes jurados del MAEC, ya que la misma corre a cargo de la Oficina de Interpretación de Lenguas, en cuyo seno se establecen perfiles diferenciados para traductores de directa, de inversa e intérpretes. La inclusión a partir de 1996 de una prueba para medir la competencia comunicativa en la $\mathrm{L}_{2}$ no deja de resultar insuficiente, lo que permite que lo ya expuesto por Giambruno (1997: 245) respecto al hecho de que "the exam included no oral exercise whatsoever, be it strictly from the foreign language to Spanish or in both directions, obvioulsy disqualifies it as a performance-based exam for court interpreting", siga siendo aplicable en la actualidad. De hecho, tal y como se ha comentado con anterioridad, a pesar del cambio en la normativa reguladora de acceso al nombramiento de intérprete jurado, en la última convocatoria de exámenes (octubre de 20Io), no se introdujo ningún cambio en el tipo de pruebas (MAEC, 20IO).

En el caso de los intérpretes jurados de Cataluña, donde sí se incluye una prueba de interpretación (cuya estructura es evidentemente mejorable), se establecen además acreditaciones claramente diferenciadas entre traductores e intérpretes. Si bien, a priori, esa solución se ajusta a las prácticas existentes en países como 
TABla 4. Tipologías teXtuales En idiomas distintos AL INGLÉS

\begin{tabular}{|c|c|c|c|c|}
\hline Sistema & Idioma & Traducción directa & Traducción inversa & Traducción directa 2 \\
\hline IJMAECo6 & Ruso & $\begin{array}{l}\text { Extracto de obra literaria } \\
\text { (Dostoyevsky) }\end{array}$ & $\begin{array}{l}\text { Extracto de artículo periodís- } \\
\text { tico sobre conducción y estrés } \\
\text { (obras de la M-3o de Madrid) }\end{array}$ & $\begin{array}{l}\text { Extracto de la ley de } \\
\text { registro de derechos } \\
\text { de propiedad sobre } \\
\text { inmuebles y transac- } \\
\text { ciones con ellos. }\end{array}$ \\
\hline \multirow{3}{*}{ IJMAECo7 } & Francés & $\begin{array}{l}\text { Reseña periodística sobre un } \\
\text { ensayo relativo a la historia de } \\
\text { la esclavitud }\end{array}$ & $\begin{array}{l}\text { Extracto de artículo periodís- } \\
\text { tico sobre los negocios de los } \\
\text { descendientes del dictador F. } \\
\text { Franco }\end{array}$ & $\begin{array}{l}\text { Extracto de reperto- } \\
\text { rio jurídico relativo a } \\
\text { determinado tipo de } \\
\text { acciones }\end{array}$ \\
\hline & Alemán & $\begin{array}{l}\text { Extracto de artículo periodís- } \\
\text { tico sobre la trivialidad con } \\
\text { la que la ciudadanía trata la } \\
\text { política }\end{array}$ & $\begin{array}{l}\text { Extracto de artículo periodís- } \\
\text { tico sobre la situación políti- } \\
\text { co-económica de Brasil }\end{array}$ & $\begin{array}{l}\text { Extracto de nota de } \\
\text { prensa del Tribunal } \\
\text { Constitucional alemán } \\
\text { sobre determinado } \\
\text { procedimiento relacio- } \\
\text { nado con la normativa } \\
\text { de insolvencia }\end{array}$ \\
\hline & Ruso & $\begin{array}{l}\text { Extractos de artículo perio- } \\
\text { dístico sobre política rusa } \\
\text { (comentario sobre la entrevista } \\
\text { de Zhirinovskiy con Putin) }\end{array}$ & $\begin{array}{l}\text { Extractos de artículo periodís- } \\
\text { tico sobre la última película de } \\
\text { Antonio Mercero }\end{array}$ & $\begin{array}{l}\text { Extractos del código } \\
\text { civil ruso (jurisdicción } \\
\text { y competencias de los } \\
\text { tribunales) }\end{array}$ \\
\hline \multirow{3}{*}{ IJMAECo8 } & Francés & $\begin{array}{l}\text { Extracto de artículo de opi- } \\
\text { nión sobre las consecuencias } \\
\text { sociales de la globalización y } \\
\text { las economías emergentes }\end{array}$ & $\begin{array}{l}\text { Extracto de artículo de opi- } \\
\text { nión sobre la viudez femenina }\end{array}$ & $\begin{array}{l}\text { Extracto sobre decreto } \\
\text { regulador de la comi- } \\
\text { sión de control de los } \\
\text { mercados públicos }\end{array}$ \\
\hline & Alemán & $\begin{array}{l}\text { Extracto de artículo de opi- } \\
\text { nión sobre la política editorial } \\
\text { que prima determinadas obras } \\
\text { y merma el espíritu creador de } \\
\text { los escritores. }\end{array}$ & $\begin{array}{l}\text { Extracto de artículo perio- } \\
\text { dístico sobre la emancipación } \\
\text { juvenil en España en tiempos } \\
\text { de crisis }\end{array}$ & $\begin{array}{l}\text { Extracto de sentencia } \\
\text { de tribunal federal } \\
\text { sobre apelación en un } \\
\text { caso de publicidad de } \\
\text { telefonía móvil enga- } \\
\text { ñosa }\end{array}$ \\
\hline & Ruso & $\begin{array}{l}\text { Extracto de artículo periodís- } \\
\text { tico sobre declaraciones del } \\
\text { presidente ruso en torno al } \\
\text { conflicto de Osetia del Sur. }\end{array}$ & $\begin{array}{l}\text { Extractos de artículo perio- } \\
\text { dístico sobre el fotógrafo de } \\
\text { Fidel Castro. }\end{array}$ & $\begin{array}{l}\text { Extracto de contrato } \\
\text { de compraventa de } \\
\text { vivienda }\end{array}$ \\
\hline
\end{tabular}


TABla 4. (cont.)

\begin{tabular}{|c|c|c|c|}
\hline Sistema & Idioma & Traducción directa & Traducción inversa \\
\hline \multirow{5}{*}{ TIJCATO8 } & Castellano & Extractos de Demanda de Juicio de Cognición & \multirow{5}{*}{$\begin{array}{l}\text { Extracto de artículo periodís- } \\
\text { tico sobre mujeres emprende- } \\
\text { doras. } \\
\text { Editorial sobre identidad cul- } \\
\text { tural catalana } \\
\text { Extracto de un artículo de } \\
\text { opinión sobre la inconstitucio- } \\
\text { nalidad de las leyes } \\
\text { Extracto de la escritura nota- } \\
\text { rial de constitución de una } \\
\text { sociedad cooperativa catalana } \\
\text { limitada }\end{array}$} \\
\hline & Francés & Extractos sentencia por recurso de casación & \\
\hline & Alemán & $\begin{array}{l}\text { Contrato de alquiler-cesión de obras de arte } \\
\text { entre museos }\end{array}$ & \\
\hline & Ruso & $\begin{array}{l}\text { Extractos de la Ley federal de sociedades de } \\
\text { accionistas. }\end{array}$ & \\
\hline & Chino & $\begin{array}{l}\text { Contrato modelo de cesión administrativa para } \\
\text { uso y explotación de un terreno de titularidad } \\
\text { pública }\end{array}$ & \\
\hline \multirow[t]{2}{*}{ MJUOI } & Francés & Extracto noticia periodística sobre adopción & $\begin{array}{l}\text { Extracto de noticia perio- } \\
\text { dística sobre falsificación de } \\
\text { documentos }\end{array}$ \\
\hline & Portugués & Extracto de texto literario & Extracto de texto literario \\
\hline \multirow[b]{2}{*}{ MJUO2 } & Francés & Extracto noticia periodística de temática judicial & $\begin{array}{l}\text { Extracto sentencia del Tribu- } \\
\text { nal Supremo }\end{array}$ \\
\hline & Chino & $\begin{array}{l}\text { Texto sobre la auditoría en derecho administra- } \\
\text { tivo chino }\end{array}$ & $\begin{array}{l}\text { Extracto sentencia del Tribu- } \\
\text { nal Constitucional }\end{array}$ \\
\hline MIRO6 & \multirow{2}{*}{\multicolumn{3}{|c|}{$\begin{array}{l}\text { N/A: se emplearon los mismos textos (tanto para directa como para inversa) en las distintas } \\
\text { combinaciones lingüísticas. }\end{array}$}} \\
\hline MIRO7 & & & \\
\hline \multirow{7}{*}{$\begin{array}{l}\text { MJU- } \\
\text { MIRO9 }\end{array}$} & Francés & $\begin{array}{l}\text { Extracto de Orden Europea de Detención (des- } \\
\text { cripción de los hechos por los que se insta) }\end{array}$ & $\begin{array}{l}\text { Fragmento de una Decisión } \\
\text { marco de la UE sobre la lucha } \\
\text { contra el terrorismo }\end{array}$ \\
\hline & Arabe & $\begin{array}{l}\text { Resolución judicial del tribunal de apelación } \\
\text { Beirut }\end{array}$ & \multirow{3}{*}{$\begin{array}{l}\text { Nota de prensa sobre la apro- } \\
\text { bación, por parte del Consejo } \\
\text { Europeo, de un plan para la } \\
\text { mejora de la seguridad en } \\
\text { materia de explosivos }\end{array}$} \\
\hline & Portugués & Artículo de opinión sobre la crisis mundial & \\
\hline & Alemán & $\begin{array}{l}\text { Artículo de prensa sobre un juicio celebrado en } \\
\text { Alemania por un presunto asesinato originado } \\
\text { por disputas en torno a los residuos del jardín. }\end{array}$ & \\
\hline & Chelja & \multirow{2}{*}{$\begin{array}{l}\text { Cuentos leídos por el examinador para realizar } \\
\text { traducción escrita en castellano }\end{array}$} & \multirow{3}{*}{$\begin{array}{l}\text { Dada la naturaleza eminente- } \\
\text { mente oral de estas lenguas/ } \\
\text { variantes lingüísticas, no existe } \\
\text { prueba de traducción inversa } \\
\text { y la de traducción directa es } \\
\text { ligeramente diferente. }\end{array}$} \\
\hline & Bereber & & \\
\hline & Dariya & $\begin{array}{l}\text { Artículo de prensa sobre la detención de unos } \\
\text { malhechores leído por el examinador para reali- } \\
\text { zar traducción escrita al castellano. }\end{array}$ & \\
\hline \multirow[t]{2}{*}{ ANDO9 } & Francés & $\begin{array}{l}\text { Extractos de la exposición de motivos de la } \\
\text { Decisión no I983/2006/CE del Parlamento } \\
\text { Europeo y del Consejo de I8 de diciembre de } \\
\text { 2006 relativa al Año Europeo del Diálogo Inter- } \\
\text { cultural (2008) }\end{array}$ & \multirow[t]{2}{*}{$\begin{array}{l}\text { Síntesis del Informe anual } \\
\text { 2oo6 sobre Derechos Huma- } \\
\text { nos del Parlamento Europeo }\end{array}$} \\
\hline & Árabe & $\begin{array}{l}\text { Extractos del reglamento de régimen interno del } \\
\text { Consejo de Seguridad de Naciones Unidas }\end{array}$ & \\
\hline
\end{tabular}


Australia y tiene en cuenta la especificidad de dos actividades que, si bien análogas, presen$\tan$ algunas diferencias, cabría preguntarse si, habida cuenta del desconocimiento existente en nuestro país en torno a traductores e intérpretes, acaso una doble acreditación no contribuya a generar más confusión aún si cabe sobre la profesión. Mención aparte merece el análisis concreto de la prueba de interpretación planteada que, de mantener el mismo tipo de situaciones y de complejidad entre sesiones, puede plantear algunas dudas en cuanto a si cumple con los criterios de validez y autenticidad, en definitiva, si es suficiente o no para garantizar que el intérprete desempeñe adecuadamente su labor en cualquier tipo de situación donde se requieran sus servicios.

\section{Deficiente concepción y desarrollo de las pruebas de acreditación de traductores jurados}

Es evidente que, en lo concerniente a las pruebas de traducción, el sistema de acreditación del MAEC, según lo que vienen recogiendo los estudios citados y lo recogido en este artículo, está necesitado de una profunda reforma en sus planteamientos más básicos, fundamentalmente en lo relativo a los parámetros recogidos al inicio de esta contribución: naturaleza de la prueba, validez, fiabilidad y autenticidad de las tareas propuestas. Para ello sería crucial que se procediese, en primer lugar, a definir el propio constructo como sugiere Angelelli (2009). Entre las medidas que se podrían adoptar estarían el que las unidades evaluables de cada texto/discurso fuesen predeterminadas, que se establecieran claramente los umbrales de superación de las pruebas, que los candidatos contasen con información detallada sobre el contenido de las pruebas, tipologías textuales, criterios de evaluación, etc. Y más importante aún si cabe, que los propios responsables de la administración de la prueba procediesen a su diseño en colaboración con expertos en evaluación e investigadores del ámbito de los Estudios de Traducción e Interpretación.

\section{Deficiente concepción y desarrollo de las pruebas de acreditación de traductores jurídicos en plantilla}

Mientras la Administración se empeñe en mantener un nivel de cualificación académica de acceso a todas luces inadecuado ( $c f$. tabla 3 ) y no establezca cauces de colaboración con expertos universitarios en el campo de la traducción y la interpretación será difícil poner solución a los problemas que presentan las pruebas analizadas. Así, los ejercicios de traducción que se han venido diseñando hasta la fecha adolecen de una clara falta de fiabilidad, validez y comparabilidad tanto entre convocatorias como entre combinaciones lingüísticas, como se ha podido observar.

Curiosamente, en el caso de Andalucía resulta paradójico comprobar que, a pesar de ser necesario estar en posesión de una titulación universitaria en Traducción e Interpretación para poder presentarse al examen, el régimen de las pruebas difiere de la labor diaria del traductor-intérprete judicial. Además, cabría plantearse si en las condiciones de examen planteadas las pruebas permiten efectivamente seleccionar a aquellos candidatos más capacitados en lo que a competencia traductora se refiere.

\section{Medidas correctoras a medio y largo plazo}

En el caso concreto de las acreditaciones profesionales como traductor y/o intérprete jurado, es cierto que el proceso de Bolonia y la introducción de los nuevos títulos de grado y posgrado exigían reformar los aspectos relativos al acceso mediante exención de examen para los 
licenciados en traducción e interpretación, lo que abría la puerta a la posibilidad de acometer una profunda reforma del sistema de acreditación $^{12}$. Lamentablemente esta reforma se ha limitado, por el momento, a suprimir la vía de acceso mediante exención de examen (cf. Vigier, 20IO; MAEC, 2009) y en la primera convocatoria de exámenes tras la reforma (octubre de 2010) se ha constatado que el formato de las pruebas sigue siendo el mismo, como ya se ha dicho. En el caso de Cataluña ya se están dando los primeros pasos para reformar igualmente el sistema, desconociéndose el alcance de tal medida, y en el País Vasco, donde en junio de 2010 se inició la implantación del nuevo sistema de acreditación para traductores e intérpretes jurados de euskera ${ }^{13}$, también se mantienen contactos entre responsables de la administración, asociaciones profesionales y expertos universitarios en traducción e interpretación, tendentes a diseñar un sistema coherente y que responda verdaderamente a las necesidades de la profesión.

En lo relativo a los sistemas de acreditación de profesionales en plantilla, sólo su correcto encuadramiento laboral permitiría requerir formalmente a los candidatos las destrezas y cualidades profesionales fundamentales que les permitan enfrentarse, con garantías, a las

I2 La primera versión de esta colaboración se entregó para su valoración y publicación cuando el Ministerio de Asuntos Exteriores abrió el periodo de presentación de alegaciones a su proyecto de reforma del Real Decreto que regula la profesión de intérprete jurado (noviembre de 2009). Entre las novedades planteadas se introduce el cambio de denominación oficial, que pasa a ser "traductor-intérprete jurado", como ya se ha dicho.

${ }_{13}$ Información recabada en entrevista personal con $\mathrm{D}^{\mathrm{a}}$. Lurdes Auzmendi, responsable de política lingüística del Departamento de Cultura del Gobierno Vasco, en octubre de 2009. En junio de 2010 (BOPV 28 de junio de 2010) se realizó una convocatoria extraordinaria para acreditar a traductores-intérpretes jurados de euskera-castellano, fundamentalmente a través de la homologación de otras acreditaciones, estudios, experiencia profesional, etc. tipologías textuales y contextos en los que se requiere interpretación con los que han de enfrentarse a diario. Es evidente que, a día de hoy, existe una gran brecha entre el nivel y los requisitos de acceso, el contenido de las pruebas de acreditación y el desempeño diario de la profesión. No podemos pasar por alto, no obstante, que este cambio, por si sólo, no servirá de nada si el régimen de acceso no se concibiese y desarrollase partiendo de nociones, ya definidas, como la validez, frabilidad y autenticidad de las propias pruebas.

No se puede olvidar aquí el papel que las iniciativas promovidas en el seno de la Unión Europea están llamadas a desempeñar en nuestro país en lo relativo a la introducción de mejoras en los sistemas de acreditación y en la propia profesionalización de la actividad de traductores e intérpretes jurídicos. A pesar de que estas iniciativas se circunscriben al ámbito penal, no nos cabe la menor duda de que pueden tener su influencia también en otros ámbitos.

Entre estas iniciativas destacan la aprobación de la Directiva sobre el derecho a interpretación y a traducción en los procesos penales (Parlamento Europeo, 20Io), texto que en cierto modo resulta de la Decisión Marco y de las recomendaciones ya aludidas al inicio de este trabajo y que no llegaron a entrar en vigor. En esta nueva directiva se puede destacar, entre otras cuestiones, el artículo 5 relativo a la calidad de la traducción y la interpretación, según el cual «los Estados miembros tomarán medidas concretas para garantizar que la interpretación y la traducción facilitadas se ajusten a la calidad exigida [...]» $\mathrm{y}$ «se esforzarán por establecer un registro de registros de traductores e intérpretes independientes debidamente cualificados», lo que puede contribuir a la mejora de aspectos varios vinculados a la profesión, como los propios procedimientos de acreditación conducentes a 
la inclusión en los citados registros. Asimismo, el artículo 6 de esta directiva contiene un llamamiento expreso a que el resto de operadores jurídicos conozcan el papel que desempeña el intérprete y las particularidades de la comunicación a través del mismo.

En definitiva, y a la espera de la transposición de la citada directiva a la normativa española, se hace necesaria una estrecha colaboración entre los propios profesionales de la traducción e interpretación jurídica (quizá a través de las asociaciones existentes), los investigadores y docentes universitarios del campo de la traducción e interpretación jurídica-judicialjurada, el resto de operadores jurídicos y la propia administración al objeto de desarrollar unos sistemas de acreditación profesional adecuados que, entre otras cuestiones, contribuyan a garantizar el derecho a un juicio justo en los procedimientos y diligencias de carácter multicultural y multilingüístico.

RECIBIDO EN NOVIEMBRE DE 2009

ACEPTADO EN ABRIL DE $20 I O$

VERSIÓN FINAL DE MARZO DE 2OII

\section{REFERENCIAS BIBLIOGRÁFICAS}

Angelelli, C. (2009). «Using a rubric to assess translation ability: Defining the construct». En Angelelli, C. and H. Jacobson (eds.) Testing and Assessment in Translation and Interpreting Studies, Philadelphia: John Benjamins, pp. 13-48

Arróniz, P. (2000). «La traducción y la interpretación en la Administración de Justicia». En Kelly, D. A. (ed.) La traducción y la interpretación en España hoy: perspectivas profesionales, Granada: Comares, pp. $157^{-1} 70$

Consejo de la Unión Europea (2009). DROIPEN I33 COPEN 205. I4793/o9

García-Medall, J. (1998). «Informe sobre la traducción e interpretación juradas». En Bueno García, A. y J. García Medall (coords.) La Traducción: de la teoría a la práctica, Valladolid: Servicio de Apoyo a la Enseñanza, Universidad de Valladolid, pp. 6I-80

Generalitat de Cataluña (2000). «Decreto II9/200o, de 20 de marzo, de traducción e interpretación juradas». Diario Oficial de la Generalitat de Cataluña, $n^{\circ}$ 3IIO, 30 de marzo de 2000, [en línea]. <http://www4.gencat.cat:83/basisbwdocstotales/sframes_recerca.htm> [Consulta: io de septiembre de 2009]

Giambruno, C. (1997). Language Mediation in the Judicial System: The Role of the Court Interpreter. Tesis doctoral inédita, Dpto. de Filología Inglesa, Universidad de Alicante

Hewitt, W.E. (Dir.) (1995). Court Interpretation: Model Guides for Policy and Practice in the State Courts [en línea]. Williamsburg: National Center for State Courts, <http://www.ncsconline. org/wc/publications/Res_CtInte_ModelGuidePub.pdf> [Consulta: 23 de septiembre de 2009]

Kelly, D. (2005). A Handbook for Translator Trainers, Manchester/Northampton: St. Jerome

Mayoral, R. (2000). «Consideraciones sobre la profesión de traductor jurado». En Kelly, D. A. (ed.). La traducción y la interpretación en España hoy: perspectivas profesionales, Granada: Comares, pp. II7-I44

(2003). «Los cambios en la profesión del traductor o intérprete jurado en España». En Valero Garcés, C. (ed.). Traducción e Interpretación en los Servicios Públicos. Contextualización, Actualización y Futuro, Granada: Comares, pp. I27-I32

Ministerio de Asuntos Exteriores (1996). «Orden de 8 de febrero de 1996 por la que se dictan las normas sobre los exámenes para el nombramiento de Intérpretes Jurados», Boletín Oficial del Estado, no 47 , 23 de febrero de 1996, [en línea]. <http://www. boe.es/boe/dias/r996/o2/23/pdfs/Ao6876-06878. pdf> [Consulta: Io de septiembre de 2009]

Ministerio de Asuntos Exteriores y de Cooperación (2009). «Real Decreto 2002/2009, de 23 de diciembre, por el que se modifica el Reglamento de la Oficina de Interpretación de Lenguas del Ministerio de Asuntos Exteriores, aprobado por Real Decreto 2555/1977, de 27 de agosto», Boletín Oficial del Estado, $\mathrm{n}^{\mathrm{O}}$ 309, 24 de diciembre de 2009, [en línea]. <http://www.boe.es/diario_boe/ txt.php?id=BOE-A-2009-20767> [Consulta: ıo de enero de 20IO] 
(20I0). «Resolución de 30 de septiembre de 20io, de la Subsecretaría, por la que se convocan exámenes para nombramiento de Traductores-Intérpretes Jurados», Boletín Oficial del Estado, no 249, I4 de octubre de 20Io, [en línea]. <http://www.boe. es/diario_boe/txt.php?id=BOE-A-20I0-I569I> [Consulta: I4 de octubre de 20io]

Ortega Herráez, Juan M. (20II). Interpretar para la Justicia. Granada: Comares.

Ortega Herráez, J. M., S. Plaza, C. Fiol y N. Hernández (2007). «Los intérpretes judiciales ante la Propuesta de Decisión Marco del Consejo sobre Garantías Procesales en los procesos penales en la Unión Europea». En Arangüena, C. (coord.) Garantías procesales en los procesos penales en la Unión Europea, Valladolid: Lexnova, pp. 252-272

Parlamento Europeo (2010). Directiva sobre Derecho a interpretación y a traducción en los procesos penales, [en línea]. <http://www.europarl.europa.
eu/sides/getDoc.do? type $=$ TA\&reference $=\mathrm{P}_{7}-$ TA-20I0-0220\&language $=\mathrm{ES}>[$ Consulta: $7 \mathrm{de}$ septiembre de 20Io]

Salvador, S. (2007). «L'habilitació professional de la traducció i la interpretació jurades en llengua catalana». Papers Lextra, 3, pp. 25-30. [en línea] $<$ http://www.lextra.uji.es/papers/2007/salvadoro7.pdf > [Consulta: I5 de noviembre de 2009]

Vigier, F. (2010). El nombramiento de traductoresintérpretes jurados de inglés mediante acreditación académica: descripción de la formación específica y del grado de satisfacción de los egresados, Granada: Editorial de la Universidad de Granada. [en línea] <http://www.ugr.es/ biblio/> [Consulta: 7 de septiembre de 20Io]

Way, C. (2005). La Traducción como Acción Social. El Caso de los Documentos Académicos (Español-Inglés), Granada: Editorial de la Universidad de Granada. 